\title{
Effect of breast feeding on child development: At birth and beyond
}

\author{
Saria Tasnim
}

Professor, Gynecology and Obstetrics, Department of Obstetrics and Gynecology, Institute of Child and Mother Health,

Dhaka, Bangladesh

\section{Abstract}

The effect of breast feeding on infant health and development has been the subject of scientific enquiry for decades. The association between breast feeding and early child development is also a complex issue. It has been found that determining the true influence of breastfeeding on child development is difficult for several reasons. This review has been made to explore the effect of ever breast feeding and duration of breast feeding on intelligent quotient, psychomotor and social development of the child during childhood and beyond. Breast feeding has positive effects on cognitive development of infant and it is more pronounced in premature infants. Breast feeding infants have higher intelligence quotient (IQ) than non-breast fed. The amount of mutual touch, tactile stimulation and mother's gaze to the infant are significantly elevated during breastfeeding and this has a positive influence on the child's psychological development. The impact of breast feeding on cognitive development, behavior, social adaptation and understanding of the infant needs to be emphasized during the promotion of breast feeding and early child development programs.

Keywords: Breast feeding, Cognitive development, Intelligence Quotient, Child parenting, Psychomotor development.

\section{Introduction}

Early child development encompasses a wide array of processes that take place from conception to the age of $5 .{ }^{1}$ It takes place in conjunction with growth and refers to the maturation of the function of acquiring skills, behavior and values, and adaptation with the environment. The effect of breast feeding on infant health and development has been the subject of scientific enquiry for decades. ${ }^{2}$ Hoefer and Hardy ${ }^{3}$ in 1929 described that breastfed babies have better cognitive outcomes in childhood than artificially fed ones.

Determining the true influence of breastfeeding on child development is difficult for several reasons. There are many potential confounding factors. Parental and family characteristics, maternal education, birth weight and stimulation of the child during infancy are all associated with child development. ${ }^{3}$ This means to infer that a direct causal relation is a challenge. Some authors argued that the relationship between breastfeeding and child development is manipulated by the maternal Intelligence quotient (IQ) and may give biased results. ${ }^{4}$ However, evidence shows that controlling for maternal education and IQ does not eliminate the positive effects of breastfeeding, suggesting that maternal IQ is not always responsible for results. 5

The aim of this review was to explore the evidences regarding the effect of breast feeding and length of time for which the child is subject to breast feeding on cognitive development, psychomotor and social development, the mental health of the child during childhood and beyond, and parenting.

\section{Practice Points}

- Breast feeding has a positive influence on early child development.

- Premature babies benefited more than those born at term with regard to cognitive development through breast feeding.

- The duration of breast feeding is important for cognitive development.

- Breast feeding for 6 months has a stronger effect than breast feeding for 4 months and breast feeding for 4 months has a stronger effect than not breast feeding at all.

- Benefits of breast feeding in relation to cognitive development and behavior of serial adaptation should be emphasized during breast feeding promotion programs.

\section{Materials and methods}

A literature review on breast feeding and early child development was undertaken using Medline. The search strategy focused on the following key words: 'early child development', 'duration of breast feeding', 'exclusive breast feeding', 'cognitive development', 'intelligent quotient', 'composition of breast milk', 'psychological influence', and 'parenting'. The primary outcome was to find out the effect of breast feeding patterns and duration on different components of child development during infancy and beyond.

Correspondence: Dr Saria Tasnim, Professor Obstetrics \& Gynecology. Institute of Child and Mother Health, Matuail. Dhaka-1362, Bangladesh. E-mail: sariatasnim2007@gmail.com. 
Systematic reviews and individual study both were considered. Literature published before the last 20 years, those not in English, and those not in a peer reviewed journal were excluded.

\section{Effect of breast feeding on cognitive development}

Evidence suggests that a relationship between breast feeding and cognitive development exists. ${ }^{2}$ In relation to intelligence, the breastfed infant has been shown to have an advantage over the non-breastfed infant. ${ }^{6}$ The effect of breast feeding on cognitive development can be explained by two factors. One is the presence of essential long-chain polyunsaturated fatty acids and Decosahexaenoic acid (DHA), which are essential for brain development. ${ }^{7}$ Evidence is emerging that DHA is important in neural and visual development of preterm and, possibly, term infants. ${ }^{8}$ Breast milk also contains growth factors and hormones which influence brain biochemistry and functional development, and are not found in formula milk. ${ }^{9}$ The physical or social interaction associated with breastfeeding may stimulate cognitive development. Another potential mechanism is that formula feeding is associated with infantile infections and chronic illness, which can cause delayed developmental milestones and, in turn, later cognitive development. $^{10}$

The duration of breast feeding is also important for child development. ${ }^{2}$ Children who had been breastfed predominantly for less than four months had higher language scores than children who were never breastfed. Children who were breastfed predominantly for more than 6 months were better than children breastfed predominantly for between 4 to 6 months. Predominant breastfeeding for six months or longer was a significant predictor for improved academic scores in mathematics, reading spelling and writing. ${ }^{2}$

Oddy et $a .^{2}$ found a 3.56 point higher IQ score at six and ten years of age among children fully breastfed for more than six months than children never breastfed. Breastfeeding and not formula-feeding at birth are associated with increased probabilities of being in excellent health at 9 months. ${ }^{11}$ Breastfeeding for 6 months or more increases motor scores at 9 months. ${ }^{11} \mathrm{~A}$ meta-analysis shows that children who were breast fed were associated with 2.7 more IQ points in children of normal birth weight and 5.2 more points in children with low birth weight. ${ }^{12}$ Breastfeeding for less than four months was associated with lower developmental scores in the first three years of life. On average, breastfed children have an IQ that is approximately 5 points higher than children who are not breastfed. ${ }^{12}$

Breastfeeding has a larger effect on cognitive development in premature infants than term infants. ${ }^{13,14}$ In a study to examine the association between duration of breastfeeding and cognitive ability at 7-8 years in a birth cohort of very low birth weight infants, a longer period of breast feeding was associated with significant increases in both cognitive IQ $(\mathrm{p}<0.001)$ and performance $(p<0.05) .^{15}$ Breastfeeding is associated with a difference of 3.16 points for cognitive development when compared to formula feeding, and that was measurable through 15 years. ${ }^{15}$

Quigley et $a l .{ }^{10}$ from the United Kingdom Millennium Cohort Study used the British Ability Scales tests at the age of 5 years (naming vocabulary, pattern construction, and picture similarities subscales) and showed the mean scores for all subscales is higher among children who were breastfed compared to children who were never breastfed. ${ }^{16}$ In term children, a two-point increase in score for picture similarities (when breastfed $\geq 4$ months) and naming vocabulary (when breastfed $\geq 6$ months); whereas in preterm children, there was a 4 point increase for naming vocabulary (when breastfed $\geq 4$ months) and picture similarities (when breastfed $\geq 2$ months) and a 6-point increase for pattern construction (when breastfed $\geq 2$ months) was observed. It is suggested that breastfed children are 1 to 6 months ahead of children who were never breastfed. ${ }^{16}$

Breast feeding and not formula feeding at birth are protective against obesity and improve cognitive outcome at 24 months and 54 months. ${ }^{11}$ Prolonged breast feeding has a strong protective effect against nocturnal enuresis which may be attributed to accelerated neurodevelopmental maturation. ${ }^{17}$ Infants who were exclusively breastfed for 6 months crawled sooner and are more likely to be walking by 12 months than infants who started solid foods at 4 months. ${ }^{18}$ Infants breastfed for four months or longer had significantly higher mean scores for fine motor skills at one, two and three years. ${ }^{18}$ Prolonging breastfeeding during the weaning process may result in a better developmental performance at 12 months, possibly due to the supply of fats affecting brain composition. ${ }^{19}$ Infants (4 to 6 months old) looked at a mobile significantly longer when tested after breastfeeding. This finding suggests that breastfeeding has a substantial effect on infants' attentiveness to and interaction with their environment. ${ }^{20}$

In a study from rural Bangladesh, the cognitive development of children aged 6-23 months was assessed by the Denver developmental screening test (DDST), and the development quotient (DQ) was found to be higher in exclusively breast fed infants than nonexclusively breast feed infants. ${ }^{21}$

\section{Effect of duration of breast feeding on child behavior}

The Breastfeeding Intervention Trial (PROBIT) study group found that breastfeeding promotion intervention led to a large increase in exclusive breastfeeding at 3 months $(43.3 \%$ vs. $6.4 \%)$ and also favorably affected the breastfeeding of the subsequent child. However, there was no evidence of risks or benefits of prolonged and exclusive breastfeeding for child and maternal behavior. $^{22}$

A study from New Zealand reported that adolescents 
who had been breastfed for $\geq 4$ months when younger expressed their mothers as having been more caring and less overprotective, but had no reduction in risk for juvenile offending, substance abuse, or mental illness. ${ }^{23}$ One Danish study reported a strong association between early weaning (within the first 2 weeks of birth) and early alcoholism among adult men. ${ }^{24}$ However, some studies relating infant feeding to schizophrenia or affective disorder in adulthood reported conflicting results ${ }^{25,26}$.

Hart et $a l .^{26}$ found that one-week-old breastfed infants obtained significantly higher scores on the orientation and motor scales on the Brazelton Neonatal Behavioural Assessment Scale. Breastfed infants have better selfregulation, fewer abnormal reflexes and fewer signs of withdrawal than formula-fed infants. ${ }^{27} \mathrm{~A}$ shorter duration of breastfeeding is associated with increased risks for mental health problems through childhood and into adolescence. $^{26}$

\section{Effect on psychosocial development}

The psychosocial development of the infant is more advanced in breastfed infants during the first year of life. ${ }^{28}$ Horwood $^{28}$ followed children from birth to 18 years or the completion of high school. His study showed that breastfed children were found to be more cooperative and socially adept students the longer they were breastfed. When drop-out rates were calculated, the rate was higher among children who had been bottle -fed and lowest among those who had been breastfed equal to or longer than eight months, even when data was adjusted for maternal demographics. ${ }^{28}$

Evidence shows that the developmental domains of adaptability and communication are responsive to the effects of breastfeeding duration, with children breastfed for longer than four months being more likely to have higher scores in these domains. ${ }^{2}$ Another study demonstrated a link between an increased length of breastfeeding and mastery of developmental milestones including polysyllabic babbling. ${ }^{29}$ These results also support findings from a New Zealand cohort study that demonstrated benefits for infants breastfed for four months or longer in the domains of intelligence, comprehension and expression. ${ }^{23}$ It is suggested that non breastfed infants are $30 \%$ more likely to have developmental delays for gross motor skills. ${ }^{29}$

\section{Relation between gender and breast feeding}

Gender differences are apparent in the effect of breastfeeding on early development, whereby girls appear to be less responsive to extended breastfeeding than boys. ${ }^{23}$ A longer duration of breastfeeding remained predictive for academic achievement in ten-year-old boys for mathematics and spelling with a small but insignificant benefit for reading in girls. ${ }^{25}$ It is postulated that boys are more vulnerable to adversity during critical periods because they lack the neuroprotective effect of the higher concentration of estrodiols in girls. ${ }^{29}$ The neuroprotective components in breast milk may have greater benefits for boys. Evidence exists for sexual dimorphism in the developing brain, giving rise to gender differences in cognition and behavior. ${ }^{30}$

\section{Effect of breast feeding on parenting}

Breastfeeding may influence parenting by facilitating mother-child bonding, interaction and, indirectly, cognitive growth. ${ }^{31}$ Positive maternal contact may induce a biological response in offspring that have a positive effect on the development of neuroendocrine aspects of the stress response. ${ }^{32}$

The amount of mutual touch, tactile stimulation and the mother's gaze to the infant were significantly elevated during breastfeeding when compared to bottle-feeding. ${ }^{33}$

Mothers who breastfeed have been found to report lower levels of perceived stress and negative mood, higher levels of maternal attachment, and perceive their infants as more reinforcing than mothers who formula-feed. ${ }^{34}$ There is evidence that breastfeeding mothers hold their babies for longer and feel more confident as parents. After breastfeeding, mothers report reductions in negative mood compared to mood levels prior to breastfeeding. ${ }^{34}$ Breastfeeding also has some stress-reducing properties for mothers and assist parenting confidence. ${ }^{35}$

\section{Conclusion}

Breast feeding is the best start to an infants' life. It ensures proper nutrition for the baby and contributes to both cognitive and non-cognitive development of the child. Breast feeding infants show higher scores on IQ and on motor skills. Breast feeding also has positive influence towards the psychosocial development of the infant and improves parenting confidence. Benefits of breast feeding in terms of infant nutrition, immunity and maternal wellbeing are usually highlighted during counseling for breast feeding. However, little attention has been focused on coordinating programs of breast feeding and early child development. It is recommended that the impact of breast feeding on parenting, its effect on to cognitive development, behavior and social adaptation during infancy and beyond should also be emphasized during the promotion of breast feeding and early child care.

\section{References}

1. Tabib SMSB, Early childhood development: an emerging issue. Bangladesh Med J 2010;39 (1):28-30.

2. Oddy WH, Kendall GE, Blair E, De Klerk NH, Stanley FJ, Landau LI, et al. Breastfeeding and cognitive development in childhood: a prospective birth cohort study. Paediatr Perinat Epidemiol 2003;17(1):81-90.

3. Hoefer C, Hardy MC. Later development of breastfed and artificially fed infants. JAMA 
1929;92: 615-9.

4. Der G, Batty GD, Deary IJ. Effect of breast feeding on intelligence in children: prospective study, sibling pairs analysis, and meta-analysis. BMJ 2006;333(7575):945.

5. Bartels $\mathrm{M}$, van Beijsterveldt $\mathrm{CE}$, Boomsma DI.Breastfeeding, maternal education and cognitive function: a prospective study in twins. Behav Genet 2009;39(6): 616-22.

6. Pollock JI. Long-term associations with infant feeding in a clinically advantaged population of babies. Dev Med Child Neurol_1994 36(5): 42940 .

7. Innis SM. Polyunsaturated fatty acids in human milk: an essential role in infant development. Adv Exp Med Biol 2004;554:27-43

8. Burch EE, Hoffman DR, Uauy R, Bairch DG, Prestidge $\mathrm{C}$. Visual acuity and the essentiality of decosahexaenoic acid and arachodonic acid in the diet of tewrm infants. Paediatric Res 1998;44:201-9.

9. De Andraca I, Peirano P, Uauy R. Nutrition and care in the prenatal and neonatal period and later development: human milk is best for optimal mental development. In: Nutrition, health and child development. Research advances and policy implications. Scientific publication no. 566. Washington, DC: PAHO/University of the West Indies/The World Bank, 1998.

10. Quigley MA, Kelly YJ, Sacker A. Breastfeeding and hospitalization for diarrheal and respiratory infection in the UK Millennium Cohort Study. Pediatrics 2007;119:e837-42.

11. Belfield CR, Kelly IR. The benefits of breastfeeding across the early years of childhood. NBER Working Paper No. 164. Cambridge, MA: National Bureau of Economic Research, 2010.

12. Anderson JW, Johnstone B, Remley DT. Breast-feeding and cognitive development: a meta-analysis. Am J Clin Nutr 1999;70:525-35.

13. Flacking R, Nyqvist KH, Ewald U. Effects of socioeconomic status on breastfeeding duration in mothers of preterm and term infants. Eur $J$ Public Health 2007;17:579-8.

14. Bhutta AT, Cleves MA, Casey PH, Cradock MM, Anand KJ. Cognitive and behavioral outcomes of school-aged children who were born preterm: a meta-analysis. JAMA 2002; 288:72837.

15. Horwood LJ, Darlow BA, Mogridge N. Breast milk feeding and cognitive ability at 7-8 years. Arch Dis Child 2001; 84(Fetal Neonatal Edition): F23-F27.

16. Quigley MA, Hockley C, Carson C, Kelly Y,
Renfrew MJ, Sacker A. Breastfeeding is associated with improved child cognitive development: A population-based cohort study. $J$ Pediatr 2012;160:25-32.

17. Barone JG, Ramasamy R, Farkas A, Salman T, Tranchell J, Schneider D, et al. Breastfeeding during infancy may protect against bed-wetting during childhood. Pediatrics 2006;118 (1):254-9.

18. Dewey KG, Cohen RS, Brown KM, Reira LL. Effects of exclusive breastfeeding for four versus six months on maternal nutritional status and infant motor development: results of two randomized trials in Honduras. J Nutr 2001;131 (2):262-7.

19. Agostoni C. Breastfeeding duration, milk fat composition and developmental indices at 1 year of life among breastfed infants. Prostaglandins Leukot Essent Fatty Acids 2001;64 (2):105-9.

20. Gerrish CJ, Mennella JA. Short-term influence of breastfeeding on the infants' interaction with the environment. Dev Psychobiol 2000;36(1):40-8.

21. Khanam W, Hoque A, Rahman N, Khatoon S, Hannan A. Cognitive development of exclusively breast fed and non-exclusively breastfed infants and young chilgren in selected rural community. Bangladesh J Child Health 2007;31 (1):1-7.

22. Kramer MS, Fombonne E, Igumnov S, Vanilovich I, Matush L, Mironova E, et al. Promotion of Breastfeeding Intervention Trial (PROBIT) Study Group. Effects of prolonged and exclusive breastfeeding on child behavior and maternal adjustment: evidence from a large, randomized trial. Pediatrics 2008;121(3):e43540.

23. Goodwin DW, Gabrielli WF Jr, Penick EC, Nickel EJ, Chhibber S, Knop J, et al. Breast-feeding and alcoholism: the Trotter hypothesis. Am J Psychiatry 1999; 156 (4):650-2.

24. Leask SJ, Done DJ, Crow TJ, Richards M, Jones PB. No association between breast-feeding and adult psychosis in two national birth cohorts. $\mathrm{Br}$ J Psychiatry 2000;177:218-21.

25. Sørensen HJ, Mortensen EL, Reinisch JM, Mednick SA. Breastfeeding and risk of schizophrenia in the Copenhagen Perinatal Cohort. Acta Psychiatr Scand 2005;112 (1):26-9.

26. Hart S, Boylan LM, Carroll S, Musick YA, Lampe, RM. Brief report: Breast-fed one-weekolds demonstrate superior neurobehavioral organization. J Pediatr Psychol 2003;28(8):52933.

27. Lawrence RA. Supporting breastfeeding/early childhood social and emotion development. $2^{\text {nd }}$ ed. In: Tremblay RE, Boivin M, Peters RDeV, eds. Encyclopedia on Early Childhood 
Development [online]. Montreal, Quebec: Centre of Excellence for Early Childhood Development and Strategic Knowledge Cluster on Early Child Development; 2008:1-7. http://www.childencyclopedia.com/documents/ LawrenceANGxp.pdf (accessed July 2014).

28. Horwood LJ, Fergusson DM. Breastfeeding and later cognitive and academic outcomes. Pediatrics 1998;101(1):E9.

29. Catalano R, Bruckner T, Hartig T, Ong M. Population stress and the Swedish sex ratio. Paediatr Perinat Epidemiol 200519(6):13-20.

30. Baron-Cohen S, Knickmeyer RC, Belmonte MK. Sex Differences in the Brain: Implications for Explaining Autism. Science 2005:310(5749):819 -23 .

31. Quinn PJ, O'Callaghan M, Williams GM, Najman JM, Andersen MJ, Bor W. The effect of breastfeeding on child development at 5 years: A cohort study. J Paediatr Child Health 2001;37 (5): 465-69.
32. Huizink AC, Robles de Medina PG, Mulder EJ, Visser GH, Buitelaar JK. Stress during pregnancy is associated with developmental outcome in infancy. $J$ Child Psychol Psychiatry. 2003 Sep;44(6):810-8.

33. Lavelli M, Poli M. Early mother-infant interaction during breast- and bottle feeding. Infant Behav Dev 1998;21(4): 667-84.

34. Mezzacappa ES, Katkin ES. Breast-feeding is associated with reduced perceived stress and negative mood in mothers. Health Psychology 2002;21(2):187-93.

35. Woodward LJ, Liberty KA. 2007. Breastfeeding and Child Psychosocial Development, In: Tremblay RE, Barr RG, Peters RdeV, eds. Encyclopedia on Early Childhood Development. [online]. Montreal, Quebec: Centre of Excellence for Early Childhood Development; 2005:1-7. http://www.child-encyclopedia.com/documents/ Woodward-LibertyANGxp.pdf (accessed July 2014) 